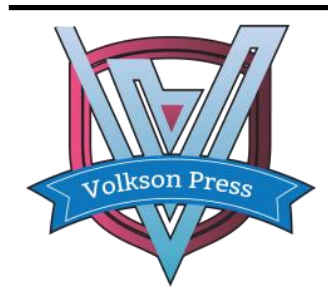

Contents List available at VOLKSON PRESS

Engineering \& Technology Innovations (ETI)

DOI : http://doi.org/10.26480/iceti.01.2017.68.70

\title{
Characteristics of Groundwater Isotopes and Ions Relationship in The Area of Seawater Intrusion
}

\author{
Zhong Du ${ }^{1,2, a}$, Huixiu $W^{2, b}$, Zengchuan Dong ${ }^{1, c}$ \\ ${ }^{1}$ College of Hydrology and Water Resources, Hohai University, Nanjing 210098, P. R. China, \\ ${ }^{2}$ Hydrology and Water Resources Survey Bureau of Liaoning Province, Shenyang 110003, P. R. China, \\ aduzhongmail@126.com, ${ }^{b}$ wuhuixiumail@126.com, ${ }^{c}$ dongzengchuan@163.com
}

This is an open access article distributed under the Creative Commons Attribution License, which permits unrestricted use, distribution, and reproduction in anv medium, provided the original work is properly cited

\section{ARTICLE DETAILS}

\section{ABSTRACT}

\section{Article History:}

Received 02 october 2017

Accepted 06 october 2017

Available online 11 october 2017

Keywords:

Stable Isotope, Sea Water Intrusion, Water-rock Interaction, Evaluation Index.

\begin{abstract}
Chemical evaluation has some shortages of analysis on water-rock reactions affecting. According to the results of isotope and chemical methods, established groundwater isotopes and ions characteristics relationship, in all ions, the decreasing order of correlation coefficient were $\mathrm{K}^{+} \& \mathrm{Na}^{+}, \mathrm{Mg}^{2+}, \mathrm{CL}^{-}, \mathrm{SO}_{4}{ }^{2-}, \mathrm{HCO}_{3}, \mathrm{Ca}^{2+}$, it indicating that different ability about ions to water-rock reactions. Finally, we select $\mathrm{K}^{+} \& \mathrm{Na}^{+}, \mathrm{CL}^{-}$as the chemical parameters to routine monitor and evaluation, and $\mathrm{CL}$ - is reasonable for single index method, the critical value is $250 \mathrm{mg} / \mathrm{L}$.
\end{abstract}

\section{INTRODUCTION}

The sea water intrusion has become a serious environment problem, which directly influences the economy development of coastal area. Based on large quantities of measured data, the authors obtained three sorts of indices for monitoring seawater encroachment, viz., chemical methods, electrical methods and isotope method [1,2]. The single-index chemical method commonly used CL-, which is the most important stable element in seawater, CL- content of $250 \mathrm{mg} / \mathrm{L}$ as critical value by most scholars to evaluation [3].Hydro-chemical monitoring indices composed of ratios of characteristic ratios and electrical indices composed of resistivity and chargeability.

Most recently, stable isotope is the new technology to trace sea water intrusion, hydrogen isotope and oxygen isotope fractionation is the trace principle. The regional groundwater recharge source is the atmospheric precipitation and part of the run-off, and the river is also converged by atmospheric aquatic. Seawater isotope value $\delta^{2} \mathrm{H}$ and $\delta^{18} 0$ were 0 , but with the evaporation enrichment, seawater isotope was enriched of varying degrees. Due to freshwater dilution in coastal, the value of $\delta^{2} \mathrm{H}$ and $\delta^{18} \mathrm{O}$ were below 0 [2-6].

The problem of the chemical method is affected by water-rock reactions [7], and the isotope monitoring is costly and can't meet the needs of the routine monitoring.

The aim of this paper is to comparison of the results of isotope and chemical methods, deduced groundwater isotopes and ions characteristics relationship, and select the appropriate evaluation chemical parameters according to the characteristics of the correlation coefficient[8-10].

\section{Materials and methods}

The area of the case is located at $123^{\circ} 23^{\prime}-125^{\circ} 43^{\prime} \mathrm{E}$ and $39^{\circ} 43^{\prime}-40^{\circ} 09^{\prime} \mathrm{N}$, between Dayang river estuary and Yalu river estuary (Fig. 1). The monitoring well-stations are phreatic water wells, distribution with invasion of the forward line was the same as the "U" shape in Fig. 1 of small round .The left point mainly monitored channel of seawater intrusion of Dayang river.The right side of the well point mainly monitored buffer with seawater intrusion of the Yalu river. The bottom of the well stations mainly monitored coastline invasion.

Stable isotopes monitoring used the same underground well stations, sampling time and water samples with chemical ions monitoring. Oxygen and hydrogen isotopes monitored by Xi'an University of Technology Key Laboratory of MAT253 mass spectrometer.The standard material was selected of VSMOW.

Water quality was examined for 7 parameters $-\mathrm{K}^{+} \& \mathrm{Na}^{+}$, $\mathrm{Ca}^{2+}, \mathrm{Mg}^{2+}, \mathrm{CL}-\mathrm{SO}_{4}{ }^{2-}, \mathrm{CO}_{3}{ }^{2-}, \mathrm{HCO}_{3}$, in the standard lab of Dan dong water resources survey bureau.

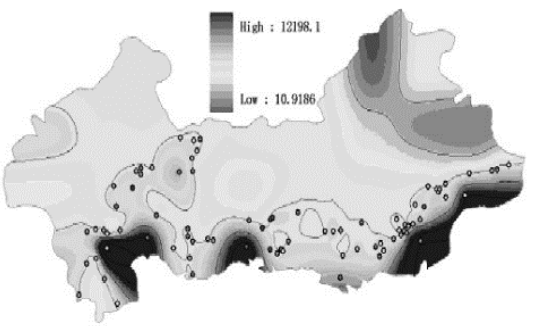

Figure 1. a) Stations of sea water instrusion with $\mathrm{CL}^{-}$values and it's $250 \mathrm{mg}$ /L isoline

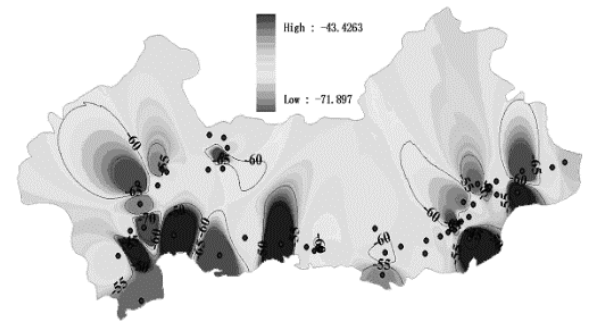

Figure 1. b) Stations of sea water instrusion with $\delta^{2} \mathrm{H}$ values 


\section{Result and discussion}

In this paper, monitoring data obtained from 48 wells, the station of sea water intrusion is similar by two methods to evaluation (Fig. 1). The correlations study of groundwater $\delta^{2} \mathrm{H}$ and $\delta^{18} \mathrm{O}$ were divided into two groups of fresh groundwater and seawater intrusion by the $250 \mathrm{mg} / \mathrm{L}$ of $\mathrm{CL}$ - ion's value. In the group of fresh groundwater:

$$
\delta^{2} \mathrm{H}=4.8^{*} \delta^{18} \mathrm{O}-16.7 \% \mathrm{R}^{2}=0.58
$$

The isotopes value were near the region of $\delta^{18} \mathrm{O}=-7 \%$, and $\delta^{2} \mathrm{H}=-50 \%$, closed to the meteoric water line (MWL) below as showed in Fig.2 [2]. This showed the set of groundwater was mainly recharged by precipitation. In the group of seawater intrusion:

$$
\delta^{2} \mathrm{H}=6.7^{*} \delta^{18} \mathrm{O}-2.5 \% \text { o, } \mathrm{R}^{2}=0.79
$$

The correlation line was near the line of the sea $\left(\delta^{2} \mathrm{H}=8^{*} \delta^{18} 0\right) \quad[2,4]$, extreme value was closed to the regional of local seawater isotope value as showed in Fig.2. This indicating the seawater intrusion and freshwater mixed.

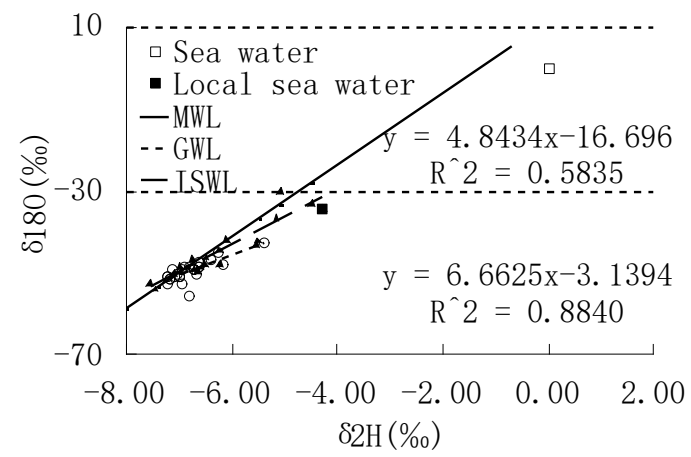

Figure 2. Groundwater isotopes characteristics in the area of seawater intrusion

In this section, all the samples, the $\mathrm{CO}_{3}{ }^{2-}$ values were all 0 , The $\mathrm{K}^{+} \& \mathrm{Na}^{+}$ were analyzed by total. All the ions were established relationship with $\delta^{2} \mathrm{H}$ and $\delta^{18} \mathrm{O}$, and the $\delta^{2} \mathrm{H}$ correlation was all better than $\delta^{18} \mathrm{O}$ except $\mathrm{Ca}^{2+}$. In anion, the correlation coefficient from big to small is $\mathrm{CL}^{-}, \mathrm{SO}_{4}^{2-}, \mathrm{HCO}_{3}^{-}$, the biggest $\mathrm{R}^{2}$ between $\mathrm{CL}^{-}$and $\delta^{2} \mathrm{H}$ was 0.74 , and $\delta^{18} \mathrm{O}$ was 0.68 . In cationic, the order of $\mathrm{R}^{2}$ is $\mathrm{K}^{+} \& \mathrm{Na}^{+}, \mathrm{Mg}^{2+}, \mathrm{Ca}^{2+}, \mathrm{R}^{2}$ was 0.81 between $\mathrm{K}^{+} \& \mathrm{Na}^{+}$and $\delta^{2} \mathrm{H}$, was 0.72 between $\delta^{18} \mathrm{O}$, and was the biggest among all ions, the decreasing order of $\mathrm{R}^{2}$ were $\mathrm{K}^{+} \& \mathrm{Na}^{+}, \mathrm{Mg}^{2+}, \mathrm{CL}^{-}, \mathrm{SO}_{4}{ }^{2-}, \mathrm{HCO}_{3}, \mathrm{Ca}^{2+}$.

As shown in Fig.3- 4, between the different ions and the isotopic values of the correlation coefficient $\mathrm{R}^{2}$ were different, indicating that different ions of the water-rock reactions. According to the size of $\mathrm{R}^{2}$, we can determine in the study area and anionic, in addition to the stable elements of $\mathrm{CL}$ - the other anions were involved in water-rock reactions. But in cationic, the $\mathrm{R}^{2}$ of $\mathrm{K}^{+} \& \mathrm{Na}^{+}$and $\mathrm{Mg}^{2+}$ were large, so they almost didn't participate in waterrock reactions. The $\mathrm{R}^{2}$ of $\mathrm{Ca}^{2+}$ and $\delta^{2} \mathrm{H}$ was smaller than the $\mathrm{Ca}^{2+}$ and $\delta^{18} \mathrm{O}$, it shows that $\mathrm{Ca}^{2+}$ had complex water-rock reactions.

In order to avoid water-rock reactions affecting chemical evaluation of seawater intrusion, so the evaluation parameter were select of $\mathrm{K}^{+} \& \mathrm{Na}^{+}$, $\mathrm{CL}$; and multi-index comprehensive evaluation were more accurately and economical evaluation of seawater intrusion.

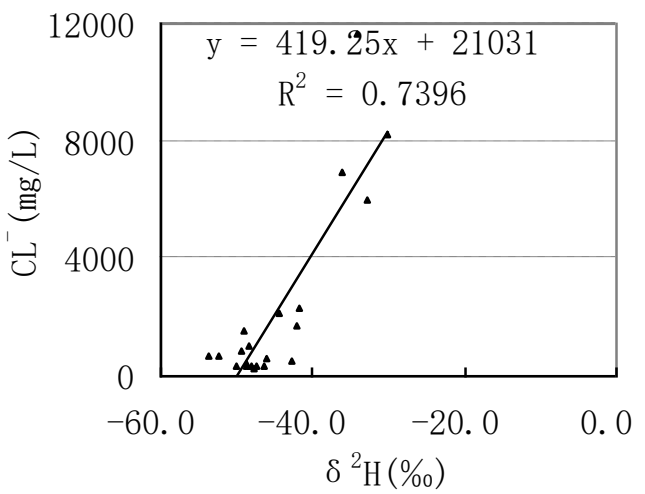

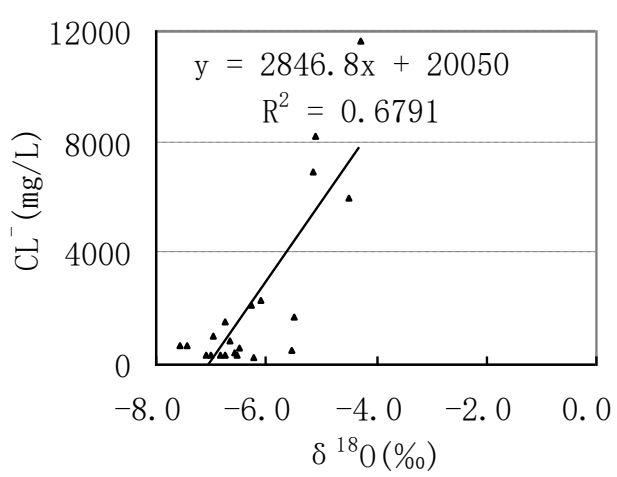
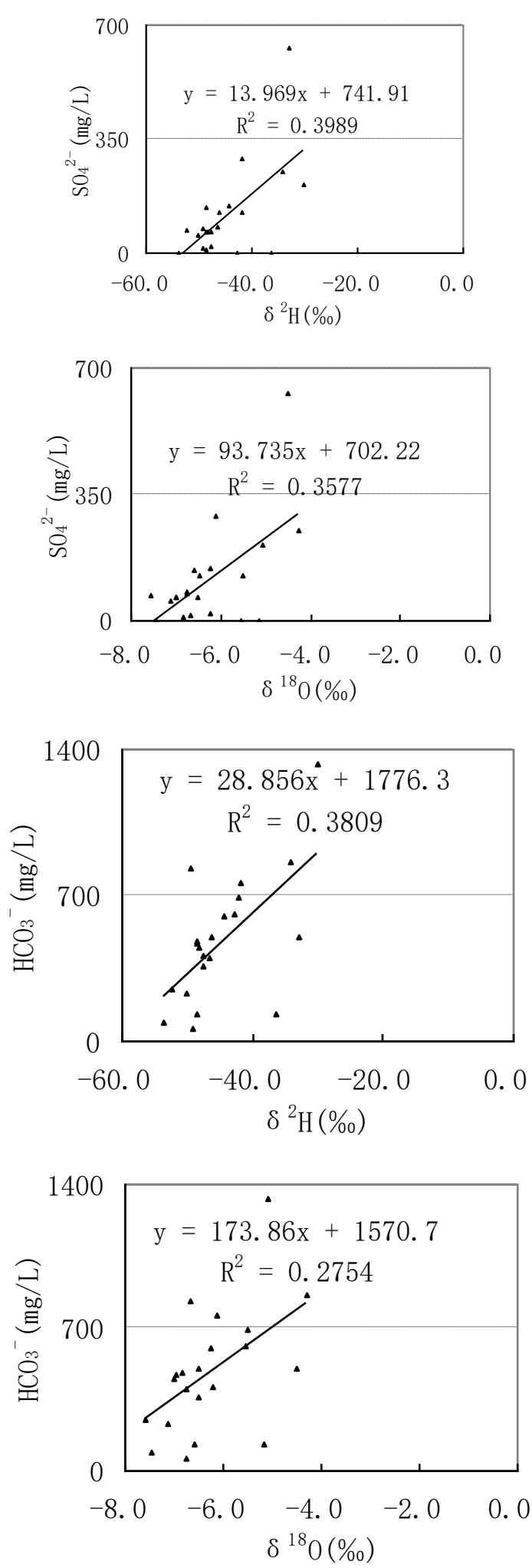

Figure 3. Relationships between isotopes and anion 

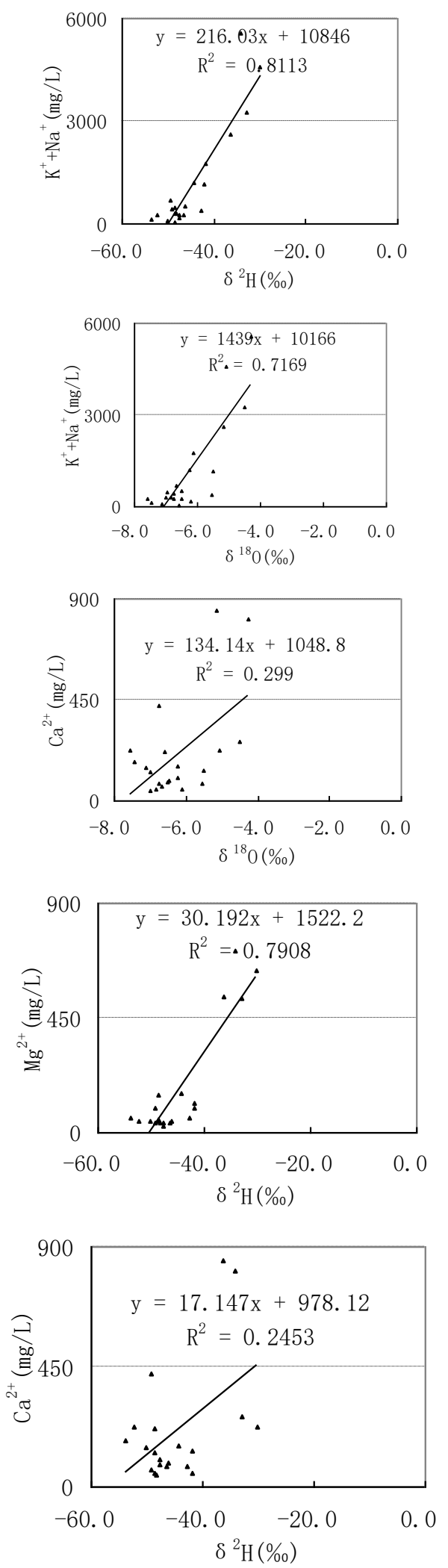

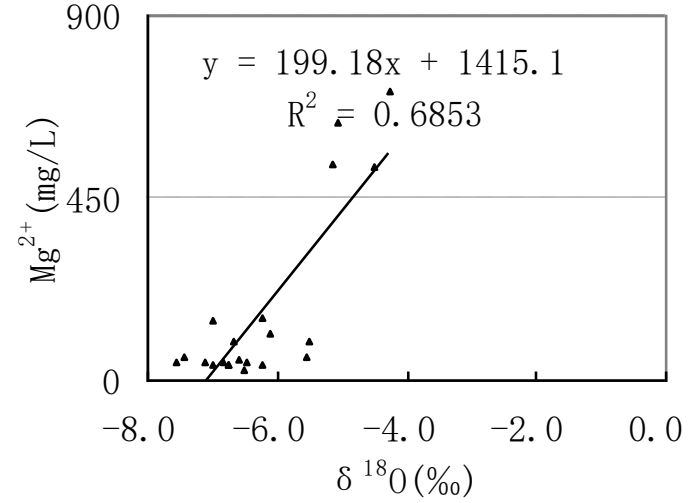

Figure 4. Relationships between isotopes and cations

\section{Conclusion}

Research has shown that evaluation results is similar by the isotope and chemical ions, but water-rock reactions affecting chemical evaluation. The decreasing order of correlation coefficient were $\mathrm{K}^{+} \& \mathrm{Na}^{+}, \mathrm{Mg}^{2+}, \mathrm{CL}-\mathrm{SO}_{4}^{2-}$, $\mathrm{HCO}_{3}^{-}, \mathrm{Ca}^{2+}$, so the chemical parameter were select of $\mathrm{K}^{+} \& \mathrm{Na}^{+}$, $\mathrm{CL}^{-}$for multi-index comprehensive evaluation, and critical value of $\mathrm{CL}^{-}$is 250 $\mathrm{mg} / \mathrm{L}$ is reasonable for single index method.

\section{References}

[1] Lan. D. Clark. "Environmental isotopes in hydrology", Science Press, China, (2006)

[2] LAEA."Guide Book of Nuclear Techniques in Hydrology", Vienna,(1983)

[3]Abarca, Elena,Vázquez-Su?é, Enric,Carrera, Jesús,Capino, Bernardo,Gámez, Desiré,Batlle, Francisco. “Optimal design of measures to correct seawater intrusion”, Water Resources ,(2006).

[4] A. A. Javadi,H. F. Abd-Elhamid,R. Farmani. "A simulation-optimization model to control seawater intrusion in coastal aquifers using abstraction/recharge wells" Int. J. Numer. Anal. Meth. Geomec, 16,(2011).

[5] Xiang yang TU,Xue ping GAO. "Application of fuzzy mathematical method in evaluation of seawater intrusion",Journal of Hydraulic Engineering, Vol. 8, P. 412, in Chinese,(2003).

[6]SINGH A. "Optimization modeling for seawater intrusion management", Journal of Hydronautics,(2014).

[7] Jilong Yang, Dongmei Han, Xiaosi SU. "The significance of environmental isotope characteristics of seawater intrusion in coastal karst area", Advances in Earth Science ,12,PP.1344-1352,(2012).

[8] Rozanski,K., Araguas Araguas,L., Gonfiantini,R.. "Isotopic patterns in modern global precipitation", Continental Isotope Indicators of Climate,11(1), PP.25-63,(1993).

[9] Farquhar G .,Ehleringer J.. "Carbon isotope discrimination and photosynthesis", Annual Review of Plant Physiology,40(1), PP,503$537,(1989)$.

[10] Coplen,T., Kendall, Hopple, J.. "Comparison of isotope reference samples", Nature, 302(2), pp.236-237, (1983). 